\title{
A Literature Review of the Practice of Educating Children about Technology Making
}

\author{
Leena Ventä-Olkkonen ${ }^{1}$, Heidi Hartikainen ${ }^{1}$, Behnaz Norouzi ${ }^{1}$, Netta Iivari ${ }^{1}$ \\ and Marianne Kinnula ${ }^{1}$ \\ ${ }^{1}$ University of Oulu, INTERACT Research Unit, Pentti Kaiteran katu 1, 90014 Oulu, \\ FINLAND \\ [ leena.venta-olkkonen, heidi.hartikainen, behnaz.norouzi, \\ netta.ivari, marianne.kinnula] doulu.fi
}

\begin{abstract}
Inspired by the Maker Movement and attempts of integrating Making into formal education of children, we have examined how practice-oriented the research on Making and education is in Child-Computer Interaction field. Our results show that despite the growing interest practice-orientation is still weak. Making efforts rarely aim for longitudinal durable patterns and practices even though practice-driven research has started to gain prominence in the whole Human-Computer Interaction field. General ideas of what Making integrated with education can be and should be seem to be well shared among practitioners, however. We demonstrate what aspects should be considered when doing practiceoriented Making research and point out gaps in our current understanding of the practice. We also provide guidelines for how to study Making in order to develop sustainable practices.
\end{abstract}

Keywords: Making, Maker Movement, Fab Lab, Makerspace, School, Education, Curriculum, Child, Youth, Teen, Teacher, Practice.

\section{$1 \quad$ Introduction}

Maker Movement has spread quickly over different continents, partly influenced by creation of the Fab Lab concept in MIT by Gershenfeld and colleagues in 2002 [58]. Making, i.e., crafting and tinkering with different materials, is actually an integral element in being human. However, when integrated with utilizing the possibilities of digital fabrication, it has been seen as revolutionary; as providing opportunities for 'ordinary people' to create something that only engineers with access to expensive machinery previously had [18]. The idea of combining digital fabrication and Making with formal education has also raised interest within researcher and practitioner communities alike. Maker Movement and Making skills are argued to have an important role in countering the digital divide by supporting development of skills in relation to digital 
technology $[11,15,32,34]$. Even calls for seeing Making related skills as allowing children to grow to be "future digital innovators" [32] or protagonists as regards technology $[37,26]$ have been presented. In line with Maker Movement, the central vision here is that children learn to see technology as something they can create and shape by themselves, not merely use [e.g. 5, 7, 17, 22, 25, 27, 31, 15].

A great research and practical challenge is how to implement such vision in the education of children. Researchers and practitioners alike have explored what Making in educational context could be. For example, in 2008 FabLab@School project in Stanford University was started and Fab Labs started to appear in K-12 schools around the world [5]. In 2011, the FabLearn conference series started as a "Digital Fabrication in Education Workshop" at Stanford University and has since been arranged yearly. In 2016, already six different FabLearn conferences/events were arranged in as many countries spreading over the globe. A related trend is that countries are placing increasing emphasis on STEM (Science, Technology, Engineering, and Mathematics) education and experimenting with integration of programming into the K-12 curricula [e.g. $2,59]$. There are also plenty of Child-Computer Interaction (CCI) studies on educating and engaging children in Making activities in the school context [e.g. 5, 11, 12, 38, 73, $78,6,30]$. The existing studies, however, mostly describe one-time and relatively short-term projects with schoolchildren, while integration of Making into basic education of children necessitates much longer and thorough engagement. So far, this has been addressed in a very limited number of studies [11, 12, 34].

We argue that there is a need for practice-oriented studies on this topic. To show this, in this study we conduct a critical review of the existing CCI literature on Making within education of children, utilizing practice approach [e.g. 40, 48, 60, 67, 81], to see how practice oriented such research currently is and what critical research gaps there can be identified. Existing Human Computer Interaction (HCI) studies have been criticized as focusing on people's short-term encounters with novel technology and as neglecting more in-depth and long-term practice studies on how such novel technology becomes embedded into and intermingled with the everyday practices of people [e.g. $48,81,82]$. In a similar vein, we point out that the existing CCI research has focused on shorter-term encounters and neglected more in-depth and long-term studies on how Making becomes embedded into and intermingled with the everyday lives of people (i.e. how it becomes a part of teachers' and pupils' practices). Thus, our definition of 'practice' relates to Making being studied in terms of its potential to become a practice (i.e. an integrated part of everyday activity). Based on the practice approach, we offer proposals on how researchers and practitioners working with children, Making, and education should conduct their studies and cultivate the emergence of practices around Making. We acknowledge that there are various views on what Making as a practice entails and on whose values and interests have been embedded within it [84]. In this paper we seek for an understanding of how Making as a practice has been approached in CCI research on children's education.

Next, we present our analytic lens together with the methodology for the literature review. Then, we outline the literature review findings, and finally summarize the results and discuss their implications for Making research, practice, and education 


\section{Theoretical Lens: Practice Approach}

Interest in practice approach originates from social sciences while practice lens has gained prominence also in technology-related disciplines such as HCI [48]. Kuutti and Bannon [48] contrast Interaction paradigm and Practice paradigm in contemporary HCI. Within Interaction paradigm, the interest is on people interacting with novel technology and on how they perceive it and what they do with it, the focus being on ahistorical events quite detached from situational aspects. Practice approach, instead, emphasizes exploring in-depth how technology is integrated into the fabric of everyday life, and focuses on how things come to matter in their context from historical, social, cultural, spatial, and temporal perspectives. Practice approach studies trajectories instead of isolated events and thus requires longitudinal studies. It acknowledges material aspects, bodily and mental activities, emotions and motivational factors, which are all studied as interconnected and inseparable elements [40, 48, 60, 67, 81].

Aspects from different practice theories have been combined into a "toolkit approach" by Nicolini [60] for studying practices. The approach guides to zooming in on a local practice and studying it from different perspectives, but also to zooming out to see the bigger picture: to studying the history behind the practice, its effects on and connections with other practices and discourses circulating around. Nicolini's toolkit represents a widely cited and respected treatment of practices and it comprehensively captures aspects of several separate, famous practice theories. Hence, it enables studying practices in quite a complexity, which is needed as practices indeed are complex.

Zooming in lens studies different aspects that relate to the local practice in a specific place and time. The focus is on actual local performances, related material and bodily aspects, aims of the practice, creativity, and durability. The zoom in lens heavily takes its inspiration from ethnomethodologically influenced approaches. [60] Regarding practices as performances, practices are basically real time doings and sayings in specific times and places and they actually exist only when enacted and re-enacted. Thus, analysis of practices should start from observing the local accomplishments. Moreover, practice always involves an active contribution of tools. Thus, the second step is to zoom in by focusing on the active role of material aspects involved in practicing such as bodily choreography and tools, artifacts, and mediation work. One should acknowledge the contribution of both material and symbolic tools. It is important to study the active role of all material artifacts and how they establish relationships between practices. The aim of the practice is also important to study to understand what the practitioner considers should be done and what is the reason for the practice. The tension between creativity and normativity needs to be studied as well to understand what the norms and rules of the practice are. Finally, durability of the practice from the perspective of legitimacy and learning is to be examined to see how the practice can become part of a larger configuration as a resource for another practice.

Zooming out lens emphasizes that practices never happen in isolation. They cannot be carried out separately from other practices: "In order to understand what happens here and now, we also need to understand what happens somewhere else" [60]. After analyzing the accomplishment of local practices, one proceeds to identifying and trailing the connections between practices, historical trajectories regarding the emergence and evolution of practices, discourses circulating around practices, and links between practices. It is important to consider how local practices are affected by other practices 
and discourses, and vice versa.

Our approach. Studying local practices usually entails long-term involvement with the practice itself through ethnographic approach. However, in this paper we use Nicolini's practice toolkit as an analytic framework to focus our attention to how the central aspects of the practices are reported in the current CCI literature on Making and education of children in the central CCI forums. This is a fresh and needed perspective in Making research in CCI - critically examining our own practice in order to be able to develop it. Utilization of a predefined categorization as an analytic framework - rather that analyzing the literature in a purely data-driven manner-helps to focus our attention to the key points in the reported practices, to spot possible research gaps, as well as to ensure that no important issues are left out. The Nicolini's toolkit of studying practices guides us to study the literature through focusing on the following nine aspects: zooming in by looking into whether and how 1) local performances, 2) aims, 3) material aspects, 4) durability, and 5) creativity have been examined in the papers, and zooming out by looking into whether and how 6) emergence and evolution of Making practice, i.e., historical trajectories, 7) effects of the practice, 8) connections between practices, and 9) discourses circulating around have been studied.

\section{$3 \quad$ Methodology for the Literature Review}

For this review, we have chosen to examine specifically how practice-oriented the research on Making and education is in the CCI field. We relied on a systematic review process of the following high quality, leading HCI and CCI conferences and journals that publish research on children: Nordic Conference on Human-Computer Interaction (NordiCHI), Human Factors in Computing Systems (CHI), Interaction Design and Children (IDC), Participatory Design Conference (PDC), Designing Interactive Systems (DIS), and International Journal of Child-Computer Interaction (IJCCI). We acknowledge that children's education and Making related papers have been published also elsewhere (e.g. in educational forums) but we decided first to focus only on the state of the art in the HCI and CCI field, to map out current knowledge and to point out research gaps and paths for future work. We also excluded some less authoritative, relatively new HCI forums that publish shorter papers on the topic (e.g. FabLearn). We maintain that in shorter papers thorough treatment of practices is unlikely. Hence, we did not carry out a systematic review of those publication forums.

The search for the conference papers was carried out using the Scopus database. The journal articles were searched using their own systems. Publication dates were limited to 2010 or later to gain as rich picture as possible of the current research. Used keywords included Making, digital fabrication, children, and education and different variations of those. A search carried out in the Scopus database is as follows: ( TITLE-ABS-KEY ( "child" OR "youth" OR "teen" OR "teenager" or "children" ) AND ( "education" OR "school" ) AND ( "Making" OR "maker" OR "fabrication" OR “3D”) ) ). A paper trail was established to keep track of what was done to avoid repeating the same search tasks during the process. The collected material was organized into an online database accessible to all authors. A total of 73 papers were found fitting our initial criteria. It was further decided to exclude papers not presenting empirical accounts of working with children and papers shorter than 4 pages. This inclusion/exclusion criteria were based 
on our own insight and judgment of the relevance of the examined studies [cf. 8, 21]. This left us with a final dataset of 45 papers. Each paper was coded into a table featuring the nine aspects of Nicolini's practice lens as columns. The coding was done by authors 1 and 2 of this paper collaboratively. The coding process was iterative, and all the materials were gone through several times to identify content in the paper representing these categories. After coding, the results were discussed between all authors and summarized in tables seen in this paper, with accompanying text. As the dataset was relatively small, quantitative analysis was not meaningful. Instead, we prepared a narrative synthesis using the collected papers to provide understanding of the current knowledge in the area and highlighting the significance of new knowledge [16].

\section{$4 \quad$ Zooming in and out}

\subsection{Zooming in: Making Activity as a Local Performance}

All of the reviewed papers featured an explanation of the making activity. The local performances were most often workshop style activities organized for children. These workshops had a predefined structure consisting of: 1) some kind of warm-up and review of the topic and the used techniques, 2) ideation and design phase, 3) Making and testing phase, and 4) Presentation and reflection phases. The warm-up phase included often an introduction and motivation to the selected topic such as energy forms [11] or archaeological findings [55]. This was followed by going through the different techniques of Making. The ideation and design phases consisted of e.g. sketching and storyboarding [30] and the actual Making phase included constructing, programming, and implementing [e.g. 78]. Often the process included also some sort of a final reflection stage, where outcomes were presented and evaluated. Emphasis of different phases varied, some highlighting and spending more time on learning the Making skills, others stressing ideation and design or Making. Workshops consisted typically of 1-10 short sessions. One-time workshops were reported in $16 / 45$ papers [e.g. 38, 42], and longerterm efforts in 18/45 publications such as bi-weekly sessions throughout a school year [61] or routines lasting for several months or even years with same group of children [e.g. 11, 85]. Drop-in Making was also mentioned in the literature [e.g. 53, 4]. In the drop-in makerspaces children were free to enter and start Making, self-motivated, without a necessity to attend a specific workshop structure.

\subsection{Zooming in: Material Aspects}

Space. All of the reviewed papers described the location where the Making practice took place. About two thirds (31/45) of locations were informal learning contexts such as after-school clubs and centers [53, 57], summer programs [69], learning and computer clubs [86], youth centers, libraries [51, 4], and museums [53]. Sometimes Making activities were conducted in more unusual settings, e.g. in youth prison [74] or a refugee camp [86]. In addition, Making in virtual space (Minecraft) was discussed [70]. Although these activities were carried out in informal learning contexts, some of them took place inside school premises and utilizing school facilities, but were not part of the curriculum [e.g. 51, 86]. About one third (13/45) were organized in school as part of 
formal teaching and curriculum. In school, the Making practice took place as part of science teaching $[55,12]$, as an elective course $[80,79,30]$ or as project weeks throughout the semester [11]. Multi-space approach was also visible in the literature. For example, Tittarelli and Iocono present a workshop program taking place in three different contexts in order to "make practices that normally take place in an archaeology lab, a fab lab and a primary school, available as resources for design." [55: pp. 3]. In [30] workshops were organized both in school premises and in the university fab lab.

Materials. Making is an activity largely dependent on materials, and they were well described in majority of $(42 / 45)$ the reviewed papers. At least five types of materials were listed in the literature: 1) Electronic components (21/45): micro-controllers, battery packs, rotating motors, vibrating motors, LEDs, paper electronics, paper circuits, programmable projections, sewable circuits, copper tape, conductive thread and fabric, coin cell batteries, sensors and actuators, Arduino board; 2) Crafting materials (18/45): cardboard, wood, paper, paint, scissors, tape, glue, pipe cleaners, fabric, colored pencils, recycled materials, Play-Doh, graphite, aluminum, beads, sequins, acrylic; 3) Devices (15/45): computers, 3D printer, laser cutter, 3D scanner, headphones, and speakers. 4) Toolkits (14/45): Arduino, Lilypad Arduino, Makey Makey, Circuit Scribe, PicoBoard, Lego WeDo and littleBits, TALKOO kit, fundakit, Dolly 2.0, Spark!, ID toolbox, Lego RCX, Crickets; 5) Software (10/45): Scratch, Meshmixer, Thingiverse platform, Tinkercad, graphics design software; The usage and rationale for choosing different materials was usually described well.

\subsection{Zooming in: Aim of the Making Activities}

The literature described at least two different types of aims for the Making practice: firstly, educating children on micro level and empowering them as makers, and secondly, higher level integration of making type working into curriculum.

Educating children. Educating children was the most often (23/45) described aim of the Making activity in the literature. Making was used for teaching different skills and empowering children as technology makers. Learning was mentioned in different levels: 1) Empowerment: advocating children's genuine participation and aiming at offering children design and technology skills and competencies [30], exploring ways to increase motivation and engagement in maker activities among girls and groups underrepresented in science and engineering [23]; 2) Learning of skills: how elements of design thinking and digital fabrication could provide pupils with new learning possibilities [73] and creating a collaborative culture of "learning and doing" [74]; 3) Selfexpression: supporting and providing means for self-expressing through Making [e.g. $62,3,38,44]$; engaging children in creating multiple representations of their personal experiences [62]; allowing a group of children and teachers to create, share, and tell stories together [3]; motivating productive and expressive hands-on Making for at-risk children [49]; 4) Related knowledge: specific learning goals such as awareness of environmental issues, ability to design creative solutions for environmental challenges [86] or teaching facts about materials [86], history [55], anatomy and physiology [61].

Integrating Making into curriculum. Higher level goal for Making practices was for example integrating Making into the science curriculum (6/45) [e.g. 11, 15]. Researchers considered how Making could have a role in the modern classroom to support 
scientific modeling [12] and specifically how 3D printing could be integrated into educational settings [6]. Making was also proposed to enrich arts curriculum e.g. in [22].

\subsection{Zooming in: Durability of the Making Practice}

Some papers explicitly stated aiming for integration of Making into the official school curricula in long term [e.g. 19, 15], hoping for durable and stable Making practice to emerge and stay as part of teaching. The papers aiming for creating a maker identity [e.g. 22] and for teaching needed skills [e.g. 20] had a similar goal, although not explicitly mentioned. Most of the papers, however, did not aim specifically for durable, continuing action patterns. Several aspects may enhance the durability of the practices of Making. Nicolini [60] names at least four of those:

Communities of Practice Enhancing Durability. People with similar skills and concerns make practices durable and stable [60]. The role of involved people is thus very important when practices are in the stage of establishment [60], whether the Making activity happens in school or in an informal learning context. Different communities can be seen as forming when introducing Making into education context. They usually consist of 1) children participating in the Making activities, 2) teachers, 3) research team members, and 4) domain experts. School administrators, classroom helpers, facilitators of the activities, parents, and other adult stakeholders collaborating with children can also be identified. Next, we open up the most prominent roles and their interaction.

Children were, naturally, an inseparable part of the reviewed literature. Importance of group work and collaboration among children was highlighted in many studies. Different ways to arrange the collaboration were tried out, for instance group members allocating different roles to each other by themselves [73], engaging in idea sharing, discussion and negotiation [20,49, 12, 79, 78, 76, 70,57], overcoming problems by observing each other [85, 57], more experienced children assisting less experienced ones (peer mentoring) [70], nomination of some children by their peers as 'experts' [86], grouping children based on knowing each other [41], or on different range of interests and skills [57] or letting children to choose their partners freely and interacting with others openly [51]. Building of community through uninterrupted natural group collaboration among children was also tried out, children playing both the roles of a teacher and a learner [74]. Within same-age-groups, teen teams were found to help each other more compared to teams consisting of younger children [65].

Teachers' presence was specified in many of the studies, mostly as providing pupils with instructions, guidance, and assistance $[1,5,15,39,73,74,86,80,20,12,30,85$, $79,72,77]$. This was particularly important when starting the activities; initially children can have a tendency of requesting help constantly from their teacher but when progressing in the activity they may come to the realization that through trying out, failing, and trying out again they can find their own way of working [73]. Sometimes teachers led the discussions of pupils [15] or the digital fabrication process [73]. Other times they joined the team of children and played the role of a learner [74], or had informal interaction with pupils while accomplishing some specific Making activities [39]. Other responsibilities of teachers mentioned included ensuring the baseline of the science knowledge of the pupils [11], providing consent for children' participation [65], assessing participants' skills [52], observing the children' activities [52], lecturing on the topic [12], dividing children into groups [30], or simply accompanying children in 
a workshop [20]. The ability of the teacher to support the complex process of digital fabrication was a considerable challenge that should be addressed [36] as well as challenges regarding hardware/software provision and teaching some complex topics to children [77]. Teachers were also specified to be closely linked with other stakeholders and they collaborated in developing the activities by providing feedback on the design concept/tool [1, 3, 5, 15, 38, 52, 66, 80, 30, 79, 72].

Research team members were reported to act as designers, developers, or revisers of the Making practices [62, 84]; instructors, tutors, or helpers in Making [15, 39, 86, 49, $47,30,75]$; lecturers providing children with introduction to the concept [14, 52]; leaders of children' activities $[15,65]$; motivators, who encourage children in the conversations [49], or supervisors of the work of junior researchers [30]. By observing children's activities and inquiring pupils' choices and actions, researchers strived to attain a deeper understanding of the creative processes of the children [73]. Sometimes research team members also assisted teachers [1] or helped pupils in Making [1, 52]. Formal and informal interaction between researchers and children was highlighted [39], formal interaction taking place when researchers acted as instructors teaching the group, informal interaction showing up through doing Making activities with children.

Different domain experts' presence was emphasized in many studies regarding their collaboration with other stakeholders and specifically with researchers. Their presence was instrumental in grounding the Making activities in real-life issues and problems, helping researchers to understand the domain-specific issues, and helping children to make their ideas come true by providing practical help and instructing and tutoring them during Making activities. Those mentioned included, e.g., game developers and content area experts [66]; an artist [63]; archaeologists [52]; a psychologist [52]; MA students participating as experience designers [52]; a fashion designer, magician, dance educator, and sport teacher [44]; teaching artists [84]; a design researcher [73]; a design team [1]; a lead designer involved in prototyping the developed sketches and helping with the manufacturing materials [1]; and experts in electrical engineering and computer science [15]. Many domain experts were mentioned in relation to planning and designing the practical work with children, such as a design researcher creating design concept template for pupils [73]; teaching artists helping in developing and revising a framework for Making [84]; design students and design researchers focusing on a digital design toolkit for children [5]; and, educational scientists providing input to the process [5]. Some domain experts such as scientists, publishers, and policy makers were mentioned as helping by giving feedback on the design concepts [5].

Parents were considered as active actors in only few studies. Involvement of parents by asking them to "post-report on the interactions of children in the days following the workshop" was suggested [13] and makerspace design was proposed to be such that it is felicitous for family engagement and children's interaction with their parents, therefore encouraging to conveying their thoughts and feelings regarding their abilities and achievements [84]. In one study, parents acted as outside audience, who contributed in structuring the feedback from other actors [56]. Many studies mentioned parents as the consent providers for their children's participation $[1,4,11,13,15,39,52,65,12]$.

Helpers, facilitators, instructors, tutors, and moderators were also identified from the studies. Classroom helpers might be present in the sessions to provide help if pupils asked for it $[14,15,63,65,6,12]$. Facilitators $[62,56,23,24,43,68,75,53]$ engaged 
in various tasks such as 1) engaging children in activities and encouraging them to express their thoughts [62], 2) adopting different facilitation approaches such as "problem-focused" or "playful" [53] and "probing into the process by asking questions" [69: pp. 3], suggesting ideas to children and discussing with them about their ideas in an open way, leading the personalization of the idea by children with some flavors of creativity [75], 4) guiding children in STEM topics additional to the project [56] and 5) encouraging children by positioning them as 'experts' [56]. Instructors were mentioned as collaborating with a teacher in designing and facilitating sessions as well as data collection [80, 41], assisting children during activities [20], or explaining the model to the children [12]. Moderators were responsible for supporting children with autism [70]. Tutors provided verbal and technical assistance [85, 78].

Learning Enhancing Durability. To achieve durable practices, the practitioners need to learn the norms of the practice. To understand development of practice, the way of how learning happens, how novices are taken as part of the practice, and who teaches whom can be examined. Concerning Making, there are some central issues the reviewed literature focused on. Regarding the norms of the Making practice, it is important to learn the practical Making skills including use of different techniques, coding, 3D modelling and printing, but also knowledge of the design process etc. As described earlier, learning in different levels was often in the focus of the reviewed literature. Teaching the needed skills was often highlighted, including for example: circuitry, coding [63], basic skills in language and numeracy, and technology [74], 3D printing [6]; laser cutting, using Makey Makey and Touch Board [30]. On higher level, also gaining digital literacy and developing maker identity were underscored in order to maintain the Making practice in the long run [e.g. 11]. Common was to empower groups of children who are underrepresented in science and engineering, for example girls [23], refugees [86], children in the risk of exclusion $[49,56]$, or children with autistic diagnosis [70]. Regarding how learning happened, teachers or instructors usually guided children in the Making practice. However, children also tutored each other as described in the previous section [74]. Newcomers could be integrated into more experienced maker groups during maker activities [57]. Learning seemed to be more self-guided and self-motivated in drop-in style makerspaces, where mentors and facilitators were there to "offer assistance when the kids encounter hurdles in the Making process." [4: pp. 596].

Tools and Instruments Enhancing the Practice Durability. Tools and instruments also maintain the durability of practices - they carry the scripts of the practices, which the designers and developers have embodied in them [60]. To be able to build durable practices, tools have to be available and functioning. Making practice is very much tool dependent. Thus, to build lasting Maker culture to schools, the first thing is to start building infrastructure. Most (32/45) of the activities in the literature were organized outside of official makerspaces (school class, computer labs, club rooms). The material provided by these spaces varied and the provided tools (devices, materials etc.) seemed to be limited, which does not enhance the durability of the practices. However, Smith et al. [73] describe Making and design activities within schools' fab lab environment. Such environment has natural enhancing effect to the establishment of Making activities as the availability of Making equipment makes it more likely for them to be used as part of teaching. Design of the space for Making needs also to be considered. In order to Making practice emerge, youth makerspaces should be designed as "interactive, 
technologically enriched spaces and programs to support youth exploration and creativity" [51: pp. 310]. In general, the material space and facilities (other than the used materials) where the Making practice took place were rarely described in detail in the literature, with a few exceptions: resource availability [53], layout and the furniture of the workshop space [38, 49, 51], and the building process of Making environment [74].

Other Practices Enhancing Making Practice Durability. Finally, the durability of the practice may be achieved by a practice becoming part of a larger configuration as a resource for another practice [60]. When Making practice becomes a natural part of everyday routines attached to other practices, it becomes persistent and durable. This indeed was the goal of the studies, which clearly stated that their goal was to integrate teaching into the curriculum [14]. When Making becomes natural part of for example STEM curriculum, it becomes a routine of everyday schoolwork. Making can also become durable as part of other recurrent practices such as e.g. after school clubs. In the studies, Making had been integrated into teen center activities [56] and after-school centers that "aim to promote the social inclusion of youth living in economically-disadvantaged communities." [57: pp: 91]. Proximity, safety, and inclusivity of the centers and "freedom of choice" can help in acquiring otherwise hard to obtain knowledge and skills and even seeing new career possibilities [57: pp. 91]. Authors [57] beautifully describe the centers as "interruptive institutions where the cycle of exclusion can be broken, and youth development addressed, over the long-term" [57: pp. 91].

\subsection{Zooming in: Creativity in the Making Practice}

Practices are re-produced every time they are performed, but at the same time, they are bound. Two practices are never identical, but still hold something in common. [60]. Creativity as such was mentioned in many of the reviewed papers. To really study creativity of a practice, however, one should be able to study it for a longer period of time, to be able to see how it changes. This sort of longitudinal tracking of Making practice is currently absent in the literature. In some cases (18/45), work with the same group of children continued on regular basis for months or years [e.g. 11]. In these cases, the authors reported how working changes within the practice while the children gained knowhow, from instruction guided to more creative and open assignment mode [11]. For example, Chu et al. [11] report that after learning Making skills within classroom constraints (lockstepped instructions, fixed goals, minimal choices, etc.) for 1.5 years, the students could produce significant technology-based science dioramas in a Maker activity that was more in line with the spirit or essence of Making. Thus, after learning basic skills, the Making practice became more open and creative.

A summary of findings generated with the zooming in lens is presented in Table 1.

Table 1. Summary of zooming out lens inspired analysis of the literature.

\begin{tabular}{ll}
\hline Zoom in Lens & Described in the reviewed literature \\
\hline $\begin{array}{l}\text { Local } \\
\text { accomplishment }\end{array}$ & $\begin{array}{l}\text { Making practice described in pre-designed workshop style structure last- } \\
\text { ing 1-10 sessions consisting of following stages with varying emphasis: } \\
\text { 1) warm-up and review of the topic and the used techniques, 2) ideation } \\
\text { and design, 3) Making and testing, and 4) presentation and reflection. }\end{array}$ \\
\hline $\begin{array}{l}\text { Material } \\
\text { aspects: Space }\end{array}$ & $\begin{array}{l}\text { (31/45) of maker activities conducted in unofficial learning contexts such } \\
\text { as after-school clubs and libraries. (13/45) in school context as part of }\end{array}$ \\
\hline
\end{tabular}




\begin{tabular}{|c|c|}
\hline & tive or science classes, as project weeks during school. \\
\hline $\begin{array}{l}\text { Material as- } \\
\text { pects: Tools \& } \\
\text { materials }\end{array}$ & $\begin{array}{l}\text { Materials and tools reported in detail; materials include crafting materi- } \\
\text { als }(18 / 45) \text {, electronic components }(21 / 45) \text {, toolkits }(14 / 45) \text {, software } \\
(10 / 45) \text {, and devices }(15 / 45) \text {. }\end{array}$ \\
\hline Aim & $\begin{array}{l}\text { Aiming to educate children (23/45) through learning Making skills and } \\
\text { knowledge, providing means for self-expression, learning general learn- } \\
\text { ing skills. Integration making into curricula mentioned as a goal in } \\
(6 / 45) \text {. }\end{array}$ \\
\hline Creativity & $\begin{array}{l}\text { No longitudinal tracking of local practices which would enable analysis } \\
\text { of how much practice varies within time. Creativity increases when chil- } \\
\text { dren have learned the basic skills needed in Making. }\end{array}$ \\
\hline $\begin{array}{l}\text { Durability: } \\
\text { Community }\end{array}$ & $\begin{array}{l}\text { Community around Making consisting of following groups: 1) Children } \\
\text { participating in the Making activities, collaborating in teams, 2) Teachers } \\
\text { providing with instructions, guidance and assistance, 3) Research team } \\
\text { members as developers of the Making process and instructors in the } \\
\text { Making activities, and 4) Domain experts grounding the activities in } \\
\text { real-life issues. }\end{array}$ \\
\hline $\begin{array}{l}\text { Durability: } \\
\text { Learning }\end{array}$ & $\begin{array}{l}\text { Learning highlighted as an important goal }(23 / 45) \text {. Learning discussed in } \\
\text { different levels. To gain durable practices, explicit Making knowledge } \\
\text { and skills and development of maker identity brought out. Learning more } \\
\text { self-guided and self-motivated in drop-in style makerspaces with help of } \\
\text { mentors and facilitators, whereas in Making workshops activities more } \\
\text { guided and structured. }\end{array}$ \\
\hline $\begin{array}{l}\text { Durability: } \\
\text { Tools \& } \\
\text { instruments }\end{array}$ & $\begin{array}{l}\text { Most of the maker activities not organized in official "makerspaces" } \\
(32 / 45) \text {. Spaces not usually described in detail. Other spaces (e.g. class- } \\
\text { rooms, computer labs, club rooms) usually used in workshop style Mak- } \\
\text { ing practices, which are time and place dependent, offer fewer equip- } \\
\text { ment for Making, and do not support that well the durability of practices. } \\
\text { Minority (12/45) of the activities organized in "official" makerspaces } \\
\text { which support better the durability of the practice by providing available } \\
\text { facilities as well as mentors and are used in both workshop style as well } \\
\text { as in drop-in Making practices. }\end{array}$ \\
\hline $\begin{array}{l}\text { Durability: } \\
\text { Other practice }\end{array}$ & $\begin{array}{l}\text { Recurrent Maker activities integrated as part of after-school programs or } \\
\text { school work }\end{array}$ \\
\hline
\end{tabular}

\subsection{Zooming out: The Emergence and Evolution of the Practices}

While zoom in lens concentrates on local practices, zoom out lens expands the scope in both time and place. One should look back in time and try to find out how the practice emerged and how it has changed since through historical investigation. Historical analysis helps to understand the power relations determining the current situation. [60]

The background of Making was typically reviewed in the literature review part of the articles. That is, the Making practice is grounded in the existing research as is typical scientific practice. However, notes about local history, stakeholders involved and their contribution, possible power struggles and varying motivations in general, and the steps taken before being able to conduct the current Making activity were scarcer. As an exception, one paper focused on different aspects of building of the Making environment: "The CLL (Constructionist Learning Laboratory) project was built upon a desire to build an alternative learning environment unencumbered to the greatest extent possible by the policies, practices and heuristics of traditional schooling. This goal was 
not entirely realized due to issues involving personnel, regulations, lack of trust and hostility imposed by the prison bureaucracy where the CLL was located." [74: pp. 487]

The historical trajectory of the local practices can still be seen implicitly through continuing elements. The literature demonstrated at least four types of historical continuity in the local practices. For example, work with a group of same children lasting for several months or years either in school [e.g. 11] or as an after-school activity [e.g. 76] was reported in 18 articles. Another example of continuity is when the same workshop structure was run for several times with different participating child groups and possibly in different settings (in 6/45 articles) [e.g. 69, 85]. The third type of continuity is when the longitudinal work of researchers around the same topic of Making continued for years (11/45). This kind of historical trajectory was visible in [e.g. 44]: "For more than a decade, we have designed, conducted and evaluated constructionist learning environments for digital fabrication with physical computing material focusing on children... In total, we conducted approximately 40 workshops with programmable construction kits (including Lego RCX, Crickets, Arduino and Arduino LilyPad)." [44: pp. $3-4]$. Continuity is also visible in the level of community where the Making practice is taking place (13/45). Making efforts can be conducted within the same school or youth center where the maker culture is thus taking root. For example, [79] described a programming focused course offered for the students of the same school four times a year as an elective. Iivari et. al. [30] reported also of long-term collaboration with researchers and local schools and Meintjes et. al. [57] described longitudinal work with the same after school center.

\subsection{Zooming out: Effects of the Practice}

Zooming out requires also studying the effects of the practices on other practices and how the local practice acts at a distance. Interesting is how the practice contributes to a wider picture and how the phenomena take place in distant times and places [60]. Most studies neglected this aspect, while Chu et al. [11] connected to this discussion the following way: "Why is it important to begin thinking about Making literacy? We expect the Maker Movement to evolve beyond being a 'movement' or a subculture. Making is poised to become a generalized rather than a specialized practice, essentially a literacy, just like textual and visual literacy today. Children learn to read till around third grade, after which they read to learn. The same may perhaps be expected for Making in the future: children may learn how to make and then use Making as a tool for learning." [11: pp. 321]. Hence, some studies touched upon the broader issue of Making practice affecting other practices: e.g., children's learning and teachers' teaching practices. Another noteworthy observation is that in this literature review we have observed similar type of practices performed in different places. Hence, Making practice seems quite bound; it is distributed through Making related courses, the Fab Lab institute, and the Fab Academy, spreading the practice around the world. The community of interested researchers also help in distributing the practices to new venues. Thus, it is not surprising that there were a lot of similarities within the Making practices.

\subsection{Zooming out: Connections Between Practices}

When zooming out, one should empirically track the associations between practices, asking how the practice is causally or materially connected with other practices. [60]. 
The reviewed literature presented many related practices that the practice of Making is related to and taking influences of. The literature connected the practice of Making for example with design practices e.g. Design thinking, [5]; Design-based learning [5]; learning practices such as Collaborative learning [63, 39]; Constructive learning / constructionism [63, 39, 12, 85, 74]; Active Learning [39]; Digital literacy [5]; education practices such as STEM \& computer science education [11, 63, 39]; computer science practices such as Electronics [13, 15, 44, 39, 54]; Programming [15, 44, 43, 63, 72, 79, 54]; Robotics [63]; Computational thinking [43]; Physical computing [43]; and art and play practices such as Storytelling [13]; Theatre [13]; Constructive play [38]; Openended Play [38]; Interactive music [38]; and gaming [72]. However, the studies did not discuss much how the Making practice is connected with the other practices of the participating children, teachers and schools.

\subsection{Zooming out: Discourses}

The spirit of empowering children as technology makers seems to be the common ethos for all, with varying flavors; that was the central academic discourse and motivating factor for the studies. None of the studies, however, examined discourses produced and reproduced in situ, in the actual Making projects, in formal education (Table 2).

Table 2. Summary of zooming out lens inspired analysis of the literature.

\begin{tabular}{|c|c|}
\hline Zoom out Lens & Described in the reviewed literature \\
\hline $\begin{array}{l}\text { Emergence } \\
\text { and evolution of the } \\
\text { practice }\end{array}$ & $\begin{array}{l}\text { Historical trajectory of local Making practice rarely described in } \\
\text { detail. Traces of historical trajectory and continuity of the local } \\
\text { practices seen in different levels: 1) Work with same group of par- } \\
\text { ticipating children continues on regular basis for months or years } \\
(18 / 45), 2) \text { Same type of workshop structure/maker activity run for } \\
\text { several times with different children and in different settings } \\
\text { (6/45), 3) Researchers' longitudinal work around same topic of } \\
\text { Making (11/45), 4) Longitudinal work with the same community } \\
\text { (e.g. school) (13/45). }\end{array}$ \\
\hline Effects of the practice & Not considered in the current literature with a few exceptions. \\
\hline $\begin{array}{l}\text { Connections between } \\
\text { practices }\end{array}$ & $\begin{array}{l}\text { Making practice linked with several other practices, most often } \\
\text { with education (e.g. collaborative and constructive learning) and } \\
\text { computer science related practices (e.g. programming, electronics } \\
\text { and robotics). In addition, also design related practices are linked } \\
\text { with Making (e.g. design thinking and participatory design). How- } \\
\text { ever, limited focus on how Making practice connects with other } \\
\text { practices of the participants in their everyday life. }\end{array}$ \\
\hline Discourses & Not considered in the current literature \\
\hline
\end{tabular}

\section{Concluding Discussion}

Inspired by the recent Maker Movement and the attempts of integrating Making into formal education of children, we conducted a review of the existing CCI literature on Making in education, utilizing the Nicolini's practice toolkit approach [60] for examining how practice-oriented such research currently is. This approach helped us make sense on the current situation in Making practice and envision how it could be better 
studied as well as integrated into the fabric of everyday life in the education of children. Next, we discuss what we can learn from this examination.

\subsection{How to Study and Nurture Durable Making Practices?}

We can summarize that the existing CCI literature on Making and education of children is not very practice-oriented. Moreover, many of the studies do not consider supporting or nurturing of durable practices for the practitioners, i.e. for children and teachers. If Making enthusiasts, both researchers and practitioners, think that all children need to learn Making skills to become digital innovators of the future [31], if the goal truly is to develop a maker mindset or identity in children $[11,15]$, to transform their education with Making [11, 12, 15], or to empower children to adopt a protagonist role as regards technology $[35,26]$, then we need to seriously consider how we can nurture durable making practices that become weaved into the fabric of everyday life. In Table 3 we give suggestions with this on mind: how the practice lens can be applied to guide and evaluate our research and practice around Making on Micro (local practice in specific time and place), Meso (related to local practice but extension in time and space), and Macro (not related to local practice) levels.

Table 3. Guidance for practice oriented CCI research on Making practices

\begin{tabular}{|c|c|c|}
\hline Level & Perspective & Questions to ask \\
\hline \multirow[t]{4}{*}{$\begin{array}{l}\text { Micro- } \\
\text { level }\end{array}$} & $\begin{array}{l}\text { Local } \\
\text { performances }\end{array}$ & $\begin{array}{l}\text { What is actually being done? What children do, what teach- } \\
\text { ers do? Is the working recurrent? How longitudinal is it? } \\
\text { Does the working progress from lock-step instructions to } \\
\text { more creative and free learning processes? }\end{array}$ \\
\hline & $\begin{array}{l}\text { Individual } \\
\text { learning }\end{array}$ & $\begin{array}{l}\text { What are children (or teachers) learning and how (e.g. prac- } \\
\text { tical Making skills, digital literacy)? Do children's and } \\
\text { teachers' skills, competencies, and maker identity develop? } \\
\text { Do they feel empowered? }\end{array}$ \\
\hline & Aim & $\begin{array}{l}\text { What is the goal of the local Making activity (e.g. specific } \\
\text { skills, learning to learn, related knowledge)? Whose goals } \\
\text { are acknowledged? }\end{array}$ \\
\hline & $\begin{array}{l}\text { Material as- } \\
\text { pects }\end{array}$ & $\begin{array}{l}\text { What materials and tools are available? What is the layout of } \\
\text { the space? How open is the space? How materials, tools and } \\
\text { space inspire, shape or limit the performances? How accessi- } \\
\text { ble are they? Are they available in the longer timespan? }\end{array}$ \\
\hline \multirow[t]{3}{*}{$\begin{array}{l}\text { Meso- } \\
\text { Level }\end{array}$} & Communities & $\begin{array}{l}\text { Who are involved? What kind of roles and responsibilities } \\
\text { are involved? How new members are taken along? Is there } \\
\text { peer learning and teaching (helping new members to join the } \\
\text { community)? }\end{array}$ \\
\hline & $\begin{array}{l}\text { Other practi- } \\
\text { ces }\end{array}$ & $\begin{array}{l}\text { Is Making part of some other activity (as part of another } \\
\text { practice)? Does school curriculum include and/or enable } \\
\text { Making activities? }\end{array}$ \\
\hline & $\begin{array}{l}\text { History of } \\
\text { the local } \\
\text { practice }\end{array}$ & $\begin{array}{l}\text { How did we get where we are? Who are/were the stakehold- } \\
\text { ers' involved? What are their interests? Who has the power? }\end{array}$ \\
\hline $\begin{array}{l}\text { Macro- } \\
\text { level }\end{array}$ & $\begin{array}{l}\text { Connections } \\
\text { between } \\
\text { practices }\end{array}$ & $\begin{array}{l}\text { To which activities (such as design, learning, IT related) the } \\
\text { current practice is connected to and how? How other prac- } \\
\text { tices are shaping Making practice? }\end{array}$ \\
\hline
\end{tabular}




\begin{tabular}{ll}
$\begin{array}{l}\text { Effects of the } \\
\text { practice }\end{array}$ & $\begin{array}{l}\text { How practice travels to other places? How the same practice } \\
\text { is expressed in another setting? How the practice in question } \\
\text { is inspiring, shaping or delimiting other practices? }\end{array}$ \\
\hline Discourses & $\begin{array}{l}\text { What are the ongoing related societal discourses (e.g. related } \\
\text { to education, skills of 21st century, constructive learning) } \\
\text { circulating around? What are the ongoing discourses in fami- } \\
\text { lies (e.g. technology is good / bad)? How these discourses af- } \\
\text { fect the local practice and vice versa? }\end{array}$
\end{tabular}

Next, we discuss our findings and guidelines on these three different levels.

Local performances. From the perspective of Nicolini's [60] toolkit approach, we can say the aspect of local performances was quite well addressed in the literature. The studies quite well described what was happening in the Making practice. We wish to point out, however, that there was a lack of observational or ethnographic studies describing in richness and detail what was happening, what the participants were saying and doing in minute detail. We think this type of inquiries are needed to understand and better support Making practice in education.

Individual learning. Learning was also acknowledged by the existing literature quite well. Mostly children's learning was addressed, but occasionally also teachers'. The current research described learning goals quite well, but it was quite vague in examining whether those were actually met. Moreover, from the perspective of durability, longer-term studies are needed.

Aims. The reviewed studies quite well addressed the aims of the practice but almost exclusively from adults' perspective, with empowerment of children, teaching children valuable skills, as their aim. Children's own aims for the practice were not discussed. The work mostly seemed not to be initiated by children or based on their own issues and interests; hence, it is not such a surprise that their aims were not the most central in these studies. We call for more child driven projects as well as for studies on the aims from children's perspective in any type of a project (in line with $[32,45]$ ).

Material aspects. Another relatively strong aspect in the studies was the acknowledgement of material issues in Making. The studies comprehensively listed the tools and technologies they utilized, even if more mundane arts and crafts materials were less well described. Usually the space where the activity took place was mentioned, but it was often not very well described: its effects on the Making practice was not contemplated upon much. The same goes for the tools and equipment in many studies: they were listed but their role in and intrigue influence on children's activities were not well addressed, even if some studies discussed their influence on creativity of children (see also $[36,46])$. The participants' detailed bodily choreographies in the space while interacting with each other and the tools and equipment in question were also neglected in the reviewed studies. This type of analysis often relies on observational or ethnographic studies with video data in situ. We invite researchers to collect such data. For durability of a practice, the material aspects are very important: the tools and equipment, if available in the longer run, capture and transmit aspects of the practice. Only few studies concentrated particularly on this aspect in the sense of building of suitable environments for Making practice. More this type of work is needed in the future.

Communities. Important is to point out that various kinds of practitioners can be identified as producers and bearers of the practice in the studies. Interestingly, these divergent groups of people were placed into various kinds of roles in the practice, too. 
Most widely discussed groups were teachers and children, who both were also assigned different kinds of roles. Mostly, however, the studies merely mentioned these groups and roles, without going into detail as regards the responsibilities, contributions and challenges associated with them. We think that practice studies focusing on the perspective of each of these stakeholder groups and their roles is warranted in the future. The groups and roles definitely have differing skills, competencies, interests, expectations, needs, and desires that should all be examined and acknowledged in the practice. Moreover, although many studies showed the variety of actors and communities that are to be involved in this practice, any group of people interacting does not automatically form a community, not to mention a community of practice $[50,86]$, which requires the group to have a joint enterprise, a shared practice supporting the enterprise, mutual relationships, a shared identity and new members learning by observing the expert member and learning by doing. The existing literature does not address these types of issues yet very well, but future studies on the emergence of communities of practice around Making in education are very much welcomed.

Other practices. For durability of a practice, it is important to connect the practice with other practices, which was indeed emphasized by the studies highlighting the need to integrate Making with education and school practices.

History of local practice. As regards zooming out, i.e., acknowledging the broader context, the studies were quite limited. The studies described the history of the Maker Movement and related research, but the local history, i.e., local happenings and trajectory behind the study, and various stakeholders with vested interests and power relations were not described. Such analyses are warmly welcomed.

Connections between practices. We were surprised to see how similar the Making practice was in the studies - carried out by different people with differing backgrounds, in different schools with their particular cultures and practices, in different countries with their specific educational systems and practices. Naturally, some differences in the studies were easily observable (e.g. regarding equipment used), but as Making practice in education involves such a variety of participants (most notably children, teachers, researchers) as bearers and producers of the practice that is embedded within such a variety of rich and evolving contexts, interesting differences should also be observable. They should also be brought up - also to reveal the variety in the values and agendas embedded in the Making practices [84]. Then again, as Maker culture is a world-wide movement; it is not that surprising that Making projects with children are somewhat similar around the world - many assumptions and principles are shared. In addition, in studies in other contexts it has been shown that children's technology use practices in public spaces bear interesting similarities to their use practices with different technology at home [82]; hence, practices may travel between contexts or heavily shape other practices. Studies have overall shown that our knowledge, background, and experiences shape our current action [29, 47]. This requires attention also in Making research: it would be interesting to study what kind of baggage the participants bring into Making, how their experiences and knowledge shape what they do, how their practices elsewhere influence their current activities, and how the experiences with Making practice influence and enrich practices elsewhere: at school, at home, during leisure time.

Effects of the practice. As regards the effects of the practice on other practices, it has already been pointed out that learning and the need for (cultural) change were highlighted in the studies, while longer term studies would be needed to really observe the 
effects, As regards participatory design, this type of attempts have been published, examining longer term influences of participatory design projects [9, 10]. Along these lines, studies inquiring the effects of these Making endeavors are also needed in the future. Effects on the participants are naturally interesting, but the practice lens guides to study effects on school practices or even educational systems. So far, the studies in their discussion sections mostly argue for such effects and give recommendations on how to achieve those, while it is yet a question mark how well they work in practice.

Discourses. As the last point, we wish to highlight that there was a lack of studies examining in situ discourses produced and reproduced during Making practice in education. Research has shown that discourses circulating around - in situ or broader ones in society - heavily influence what people say and do [e.g. 19, 28, 71]. Definitely interesting discourses on Making could be identifiable in situ by listening to how the participants talk about it, but also by carrying out broader analyses addressing talk about Making in education in society - shaping the opinions of the public as well as that of the policy makers. These studies remain yet to be carried out.

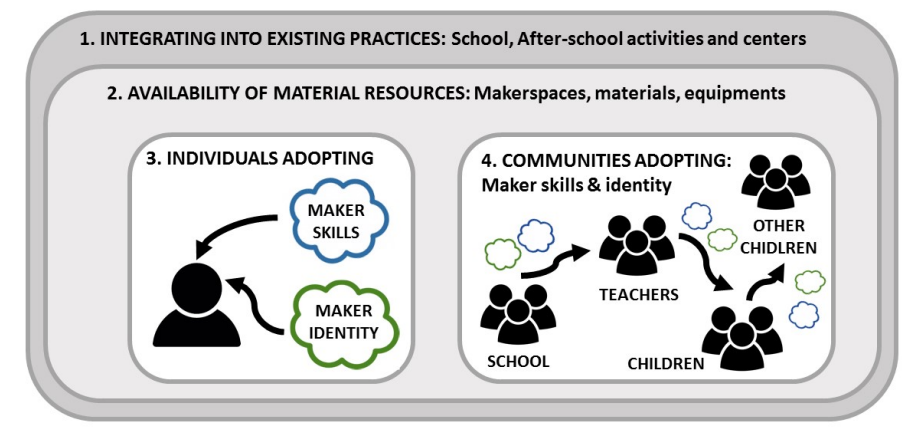

Fig. 1. Nurturing durable Making practice in education.

Way forward. The way forward in nurturing durable Making practice is demonstrated in Fig. 1. In order to develop practices that last and become durable, Making practice should be integrated with other recurrent daily practices such as schoolwork or after-school clubs. Although integrating into school curriculum would reach children in a wide spectrum, informal contexts, such as after school clubs, may be even more efficient in teaching children to become makers, as the activity is voluntary and does not have the burden of learning goals. In this endeavor, availability of material resources is critical: easy access to makerspaces with needed material and equipment as well as guidance are necessary. The participants should first learn the basic Making skills, which in the longer run should contribute to the adoption of a maker identity and ideology. In school context, it is also critical that teachers learn the Making skills and how to integrate Making naturally into everyday schoolwork. Only after that, the practice can become a durable part of education of children. To truly ensure durable practices, communities of practice should emerge, within which individuals learn from each other and novices are encultured and educated to become full members.

\subsection{Conclusion}


Previous literature reviews on Making and children have focused on Making as a social action and the histories of participants and interactions between them [34], potential of Making in empowering children to become digital innovators of the future [33], or potential on Making in the educational contexts [88; 64], while our interest has been in the potential of the practice of Making to become integrated as part of everyday activity in educational contexts. Our results show that even though Making in the context of children's education has raised much interest within both researcher and practitioner communities, it is still an undeveloped practice and much is needed to truly understand what it means to integrate Making with education of children. Many gaps exist in our current understanding of the practice but it can also be seen that some general ideas on what Making integrated with education can be and should be is surprisingly shared among the practitioners. As there is a vivid interest within practitioner communities all around the world, researchers have good possibilities to both study this emerging practice and to affect how it develops. By adopting the practice lens, it is possible to understand the Making practice in-depth as well as to help it to fit into the everyday life of schools.

We wish to point out, however, that there are also alternative ways to do practice research and we do not see the Nicolini's [60] toolkit approach as the only way forward (see also [81]). The toolkit's strength is that it very comprehensively captures aspects that are relevant in practice studies and it hence provided a very useful lens for this examination of how well practice approach has been utilized in the existing literature. However, at the same time the toolkit combines such a variety of theories and traditions that its coherence can be questioned. For a detailed practice study in practice, it might be wiser to select one of the theories Nicolini utilizes. Each of them has its own strengths and weaknesses; hence, the selection needs to be done case by case, considering the specific needs and interests of the study.

As to the limitations of this study, due to the existing research not being very practice-oriented, the number of the papers analyzed in this review is relatively small and therefore the actual practice in real life surely is more varied than pictured here. We also acknowledge that Nicolini's toolbox is meant for serving as a methodological lens for ethnographic studies. Here, we have applied it to reviewing literature which tell the interpretations and analysis of the authors of the papers, instead of the original local practices. Moreover, one could criticize the validity of the whole lens, which combines several practice theories with distinct assumptions and ontologies into one framework. Despite these weaknesses, we think that the benefits of using the analysis framework are greater than the drawbacks. By utilizing the toolbox, we are able to identify issues, which we wouldn't be able to spot without.

\section{References}

1. Angello, G., Chu, S. L., Okundaye, O., Zarei, N., Quek, F.: Making as the New Colored Pencil: Translating Elementary Curricula into Maker Activities. In Proc IDC. pp 68-78, ACM, New York (2016).

2. Balanskat, A., Engelhardt, K.: Computing Our Future: Computer Programming and Coding-Priorities, School Curricula and Initiatives Across Europe. European SchoolNet (2014).

3. Baranauskas, M. C. C., Posada, J. E. G.: Tangible and Shared Storytelling: Searching for the Social Dimension of Constructionism. In Proc IDC, pp. 193-203, ACM, New York 
(2017).

4. Bar-El, D., Zuckerman, O. and Shlomi, Y.: Social Competence and STEM: Teen Mentors in a Makerspace. In Proc IDC, pp. 595-600, ACM, New York (2016).

5. Bekker, T., Bakker, S., Douma, I., van der Poel, J., Scheltenaar, K.: Teaching children digital literacy through design-based learning with digital toolkits in schools. Int. J. ChildComp. Interact., 5(C), 29-38 (2015).

6. Berman, A., Deuermeyer, E., Nam, B., Chu, S.L., Quek, F.: Exploring the 3D Printing Process for Young Children in Curriculum-Aligned Making in the Classroom. In Proc IDC, pp. 681-686, ACM, New York (2018).

7. Blikstein, P.: Digital fabrication and 'Making'in education: The democratization of invention. In Walter-Herrmann, J. and Büching, C. eds. FabLabs: Of Machines, Makers and Inventors. transcript Verlag, 1-21 (2013).

8. Boell, S. K., Cecez-Kecmanovic, D.: On being 'systematic' in literature reviews in IS. J Inform Technol, 30(2), 1-13 (2014).

9. Bossen, C., Dindler, C., Iversen, O.: Impediments to user gains: experiences from a critical participatory design project. In Proc PDC, pp. 31-40, ACM, New York (2012).

10. Bossen, C., Dindler, C., Iversen, O. S.: User gains and PD aims: assessment from a participatory design project. In Proc PDC, pp. 141-150, ACM, New York (2010).

11. Chu, S. L., Deuermeyer, E., Martin, R., Quek, F., Berman, A., Suarez, M., Zarei, N., Nam, B., Banigan, C.: Becoming Makers: Examining "Making" Literacy in the Elementary School Science Classroom. In Proc IDC, pp. 316-321, ACM, New York (2017).

12. Chu, S.L., Deuermeyer, E., Quek, F.: Supporting scientific modeling through curriculumbased making in elementary school science classes. Int. J. Child-Comp. Interact, 16(June 2018), 1-8, (2018).

13. Chu, S. L., Quek, F., Bhangaonkar, S., Ging, A. B., Sridharamurthy, K.: Making the Maker: A Means-to-an-Ends approach to nurturing the Maker mindset in elementary-aged children. Int. J. Child-Comp. Interact, 5(sept 2015), 11-19 (2015).

14. Chu, S. L., Saenz, M., Quek, F.: Connectors in Maker Kits: Investigating Children's Motor Abilities in Making. In Proc IDC. 452-462, ACM, New York (2016).

15. Chu, S. L., Schlegel, R., Quek, F., Christy, A., Chen, K. 2017.: "I Make, Therefore I Am": The Effects of Curriculum-Aligned Making on Children's Self-Identity. In Proc CHI, pp. 109-120, ACM, New York (2017).

16. Cronin, P., Ryan, F., Coughlan, M.: Undertaking a literature review: a step-by-step approach. Br. J. Nurs., 17(1), 38-43 (2008).

17. Dougherty, D.: The maker movement. Innovations, 7(3), 11-14 (2012).

18. Gershenfeld, N.: How to make almost anything: The digital fabrication revolution. Foreign Affairs, 91(6), 43-57 (2012).

19. Halkola, E., Iivari, N., Kuure, L.: Infrastructuring as social action. In: Proc ICIS, pp. 1-19 (2015).

20. Hamidi, F., Young, T. S., Sideris, J., Ardeshiri, R., Leung, J., Rezai, P., Whitmer, B.: Using robotics and $3 \mathrm{D}$ printing to introduce youth to computer science and electromechanical engineering. In Proc CHI, pp. 942-950, ACM, New York (2017).

21. Hart, C.: Doing a Literature Review: Releasing the Social Science Research Imagination. SAGE Publications Ltd (1999).

22. Hatch, M.: The maker movement manifesto. McGraw-Hill Education, New York (2014).

23. Holbert, N.: Bots for tots: Building inclusive makerspaces by leveraging "ways of knowing". In: Proc IDC, pp. 77-88, ACM, New York (2016).

24. Holbert, N.: Leveraging cultural values and "ways of knowing" to increase diversity in makeractivities. Int. J. Child-Comp. Interact 9-10(Dec 2016), 33-39 (2016).

25. Honey, M., Kanter, D. E. eds. Design, make, play: Growing the next generation of STEM innovators. Routledge (2013). 
26. Iivari, N., Kinnula, M.: Empowering children through design and making: towards protagonist role adoption. In Proc PDC, ACM, New York (2018).

27. Iivari, N., Kinnula, M.: Inclusive or Inflexible - a Critical Analysis of the School Context in Supporting Children's Genuine Participation. In: Proc NordiCHI, pp. 1-10, ACM, New York (2016).

28. Iivari, N., Kinnula, M., Kuure, L.: With best intentions - a Foucauldian examination on children's genuine participation in ICT design. Jour Inf Tech \& Peop, 28, 2, 246-280 (2015).

29. Iivari, N., Kinnula, M., Kuure, L., Molin-Juustila, T.: Video Diary as a Means for Data Gathering with Children - Encountering Identities in the Making. Int J Hum Comput Stud, 5(5), 507-521 (2014).

30. Iivari, N., Kinnula, M., Molin-Juustila, T.: You have to start somewhere - Initial meanings making in a design and making project. In: Proc IDC, pp.80-92, ACM, New York (2018).

31. Iivari, N., Kinnula, M., Molin-Juustila, T., Kuure, L.: Multiple Voices in the Maker Movement - A Nexus Analytic Review of Children and Making Research. In Proc ECIS, pp. 1919-1933 (2017).

32. Iivari, N., Molin-Juustila, T., Kinnula, M.: The Future Digital Innovators: Empowering the Young Generation with Digital Fabrication and Making. In Proc ICIS, pp. 18 (2016).

33. Iivari, Kinnula, Molin-Juustila, Kuure. Multiple Voices in the Maker Movement - A Nexus Analytic Literature Review on Children, Education and Making. In Proc ECIS pp. 1919-1933 (2017).

34. Iversen, O.S., Smith, R.C., Dindler, C.: From computational thinking to computational empowerment: a 21st century PD agenda. In Proc PDC, pp. 1-11, ACM, New York(2018).

35. Iversen, O. S., Smith, R. C., Blikstein, P., Katterfeldt, E., Read, J. C.: Digital fabrication in education: Expanding the research towards design and reflective practices. Int. J. ChildComp. Interact., 5(Sep 2015), 1-2 (2015).

36. Iversen, O. S., Smith, R. C., Dindler, C: Child as Protagonist: Expanding the Role of Children in Participatory Design. In Proc IDC, pp. 27-37, ACM, New York (2017).

37. Jakobsen, K. B., Stougaard, J., Petersen, M. G., Winge, J., Grønbæk, J. E., Rasmussen, M. K.: Expressivity in Open-ended Constructive Play: Building and Playing Musical Lego Instruments. In Proc IDC, pp. 45-57, ACM, New York (2017).

38. Johnson, R., Shum, V., Rogers, Y., Marquardt, N.: Make or Shake: An Empirical Study of the Value of Making in Learning About Computing Technology. In Proc IDC, pp. 440451, ACM, New York (2016).

39. Jurmu, M., Ventä-Olkkonen, L., Lanamäki, A., Iivari, N., Kukka, H., Kuutti, K.: Emergent Practice as a Methodological Lens for Public Displays In-The-Wild. In Proc PerDis, pp. 124-131, ACM, New York (2016).

40. Kafai, Y., Vasudevan, V.: Hi-lo tech games: Crafting, coding and collaboration of augmented board games by high school youth. In Proc IDC, pp. 130-139, ACM, New York (2016).

41. Katterfeldt, E.-S., Cuartielles, D., Spikol, D., Ehrenberg, N.: Talkoo: A new paradigm for physical computing at school. In Proc IDC, pp. 512-517, ACM, New York (2016).

42. Katterfeldt, E.-S., Cukurova, M., Spikol, D., Cuartielles, D.: Physical computing with plug-and-play toolkits: Key recommendations for collaborative learning implementations. Int. J. Child-Comp. Interact, 17(Sep 2018), 72-82 (2018).

43. Katterfeldt, E., Dittert, N., Schelhowe, H.: Designing digital fabrication learning environments for Bildung: Implications from ten years of physical computing workshops. Int. J. Child-Comp. Interact., 5 (Sep 2015), 3-10 (2015).

44. Kinnula, M., Iivari, N., Molin-Juustila, T., Keskitalo, E., Leinonen, T., Mansikkamäki, E., Käkelä, T., Similä, M. 2017. Cooperation, Combat, or Competence Building - What Do We Mean When We Are 'Empowering Children' in and through Digital Technology Design? In Proc ICIS, pp. 21, AIS (2017). 
45. Kinnula, M., Molin-Juustila, T., Sanchez Milara, I., Cortes, M., Riekki, J.: What if It Switched on the Sun? Exploring creativity in a brainstorming session with children through a Vygotskyan perspective. Comput Support Coop Work, 26(4), 423-452, (2017).

46. Kuure, L., Halkola, E., Iivari, N., Kinnula, M., Molin-Juustila, T.: Children imitate! Appreciating recycling in participatory design with children. In Proc PDC, pp. 131-140, ACM, New York (2010).

47. Kuutti, K., Bannon, L. J.: The turn to practice in HCI: towards a research agenda. In Proc CHI, pp. 3543-3552, ACM, New York (2014).

48. Kuznetsov, S., Trutoiu, L. C., Kute, C., Howley, I., Siewiorek, D., Paulos, E.: Breaking boundaries: Strategies for mentoring through textile computing workshops. In Proc CHI, pp. 2957-2966, ACM, New York (2011).

49. Lave, J., Wenger, E.: Situated learning: Legitimate peripheral participation. Cambridge University Press (1991).

50. Lee, V. R., Lewis, W., Searle, K. A., Recker, M., Hansen, J., Phillips, A. L.: Supporting interactive youth maker programs in public and school libraries: Design hypotheses and first implementations. In Proc IDC, pp. 310-315, ACM, New York (2017).

51. Linke, R., Kothe, T., Alt, F.: TaBooGa: A Hybrid Learning App to Support Children's Reading Motivation. In Proc IDC, pp. 278-285, ACM, New York (2017).

52. Litts, B. K.: Resources, facilitation, and partner-ships: Three design considerations for youth makerspaces. In Proc IDC, pp.347-350, ACM, New York (2015).

53. Lochrie, M., Dickinson, A., Matthys, G., (...), Gradinar, A., Egglestone, P.: Co-designing a physical to digital experience for an onboarding and blended learning platform. In Proc IDC, pp. 660-665, ACM, New York (2016).

54. Marti, P., Tittarelli, M., Iacono, I.: Itinerarium: Co-designing A Tangible Journey Through History. In Proc NordiCHI, pp. 1-6, ACM, New York (2016).

55. McBeath, J. K., Durán, R. P., Harlow, D. B.: Not my gumdrop buttons! Youth tool use in designing an electronic Shrek-themed bean bag toss. In Proc IDC, pp. 61-72, ACM, New York (2017).

56. Meintjes, R., Schelhowe, H.: Inclusive interactives: The transformative potential of making and using craft-tech social objects together in an after-school centre. In Proc IDC, pp. 89-100, ACM, New York (2016).

57. Mikhak, B., Lyon, C., Gorton, T., Gershenfeld, N., McEnnis, C., Taylor, J.: Fab Lab: an alternate model of ICT for development. In Proc international conference on open collaborative design for sustainable innovation, pp. 1-7 (2002).

58. National Research Council: Successful K-12 STEM education: Identifying effective approaches in science, technology, engineering, and mathematics. National Academies Press (2011).

59. Nicolini, D.: Practice theory, work, and organization: An introduction. Oxford university press, Great Britain (2012).

60. Norooz, L., Froehlich, J.: Exploring early designs for teaching anatomy and physiology to children using wearable e-textiles. In Proc IDC, pp. 577-580, ACM, New York (2013).

61. Panjwani, A.: Constructing Meaning: Designing Powerful Story-Making Explorations for Children to Express with Tangible Computational Media. In Proc IDC, pp. 358-364, ACM, New York (2017).

62. Papavlasopoulou, S., Giannakos, M. N., Jaccheri, L.: Creative Programming Experiences for Teenagers: Attitudes, Performance and Gender Differences. In Proc IDC, pp. 565-570, ACM, New York (2016).

63. Papavlasopoulou, S., Giannakos, M. N., Jaccheri, L. Empirical studies on the Maker Movement, a promising approach to learning: A literature review. Entertainment Computing, 18(Jan 2017), 57-78 (2017).

64. Papavlasopoulou, S., Sharma, K., Giannakos, M., Jaccheri, L.: Using Eye-Tracking to Unveil Differences Between Kids and Teens in Coding Activities. In Proc IDC, pp. 171-181, 
ACM, New York (2017).

65. Radu, I., Doherty, E., DiQuollo, K., McCarthy, B., Tiu, M.: Cyberchase Shape Quest: Pushing Geometry Education Boundaries with Augmented Reality. In Proc IDC, pp. 430444, ACM, New York (2015).

66. Reckwitz, A.: Toward a theory of social practices - A development in culturalist theorizing. Eur. J. Soc. Theory, 5, 2, 243-263 (2002).

67. Richard, G. T., Kafai, Y. B.: Making physical and digital games with e-textiles: A workshop for youth making responsive wearable games and controllers. In Proc IDC, pp. 309402, ACM, New York (2015).

68. Richard, G.T., Giri, S., McKinley, Z., Ashley, R.W. Blended making: Multi-interface designs and E-crafting with elementary and middle school youth. In Proc IDC, pp.675-680, ACM, New York (2018).

69. Ringland, K. E., Boyd, L., Faucett, H., Cullen, A. L. L., Hayes, G. R.: Making in minecraft: A means of self-expression for youth with autism. In Proc IDC, pp. 340-345, ACM, New York (2017).

70. Scollon, Scollon: Nexus analysis: Discourse and the emerging internet. Routledge (2004).

71. Simões Gomes, T.S., Pontual Falcano, T., Cabral de Azeve-do Restelli Tedescoa, P.: Exploring an approach based on digital games for teaching programming concepts to young children. Int. J. Child-Comp. Interact, 16(June 2018), 77-87 (2018).

72. Smith, R. C., Iversen, O. S., Hjorth, M.: Design thinking for digital fabrication in education. Int. J. Child-Comp. Interact., 5(Sep 2015), 20-28 (2015).

73. Stager, G. S.: Papert's Prison Fab Lab: Implications for the Maker Movement and Education Design. In Proc IDC, pp 487-490, ACM, New York (2013).

74. Tan, V., Peppler, K.: Creative design process in making electronic textiles. In Proc IDC, pp. 327-330, ACM, New York (2015).

75. Tarkan, S., Sazawal, V., Druin, A., Golub, E., Bonsignore, E. M., Walsh, G., Atrash, Z. Toque: Designing a cooking-based programming language for and with children. In Proc CHI, pp. 2417-2426, ACM, New York (2010).

76. Tinapple, D., Sadauskas, J., Olson, L.: Digital culture creative classrooms (DC3): Teaching 21 st century proficiencies in high schools by engaging students in creative digital projects. In Proc IDC, pp. 380-383, ACM, New York (2013).

77. Trappe, C.: Creative access to technology: Building sounding artifacts with children. In Proc IDC, pp. 188-191, ACM, New York (2012).

78. Tsan, J., Lynch, C.F., Boyer, K. A.: “Alright, what do we need?” A study of young coders' collaborative dialogue. Int. J. Child-Comp. Interact, 17(Sep 2018), 61-71 (2018).

79. Vasudevan, V., Kafai, Y., Yang, L. Make, wear, play: Remix designs of wearable controllers for scratch games by middle school youth. In Proc IDC, pp. 339-342, ACM, New York (2015).

80. Ventä-Olkkonen, L.: The characteristics and development of urban computing practices: utilizing practice toolkit approach to study public display network. PhD dissertation Thesis, University of Oulu, Finland (2017).

81. Ventä-Olkkonen, L., Iivari, N., Kuutti, K.: Zooming in and out - Studying children's and their families' smart device practices with public and private screens. In: Proc ECCE, pp. 129-136, ACM, New York (2017).

82. Vossoughi, S. Bevan, B. Making and tinkering: a review of the literature. National Research Council Committee on Out of School Time STEM (2014).

83. Wardrip, P. S., Brahms, L.: Learning Practices of Making: Developing a Framework for Design. In Proc IDC, pp. 375-378, ACM, New York (2015).

84. Weibert, A., Marshall, A., Aal, K., Schubert, K., Rode, J.A.: Sewing interest in e-textiles: Analyzing making from a gendered perspective. In Proc DIS, pp. 15-24, ACM, New York (2014).

85. Weibert, A., Mouratidis, M., Khateb, R., Rüller, S., Hosak, M., Potka, S., Aal, K., Wulf, 
V. Creating Environmental Awareness with Upcycling Making Activities: A Study of Children in Germany and Palestine. In Proc IDC, pp. 286-291, ACM, New York (2017).

86. Wenger, E.: Communities of practice: Learning, meaning, and identity. Cambridge University Press (1998).

87. Vossoughi, S., Hooper, P. K., Escudé, M.: Making through the lens of culture and power: Toward transformative visions for educational equity. Harvard Educational Review, 86(2), 206-232 (2016). 